\title{
First derivative ATR-FTIR spectroscopic method as a green tool for the quantitative determination of diclofenac sodium
}

\section{tablets [version 1; peer review: 2 approved]}

\author{
Khairi M. S. Fahelelbom (D1, Abdullah Saleh (D1,2, Ramez Mansour (D1, Sadik Sayed ${ }^{1}$ \\ ${ }^{1}$ Department of Pharmaceutical Sciences, College of Pharmacy, Al Ain University, P.O. Box 64141, Al Ain, United Arab Emirates \\ ${ }^{2}$ Department of Chemistry, The Hashemite University, P.O. Box 330127, Zarqa, 13133, Jordan
}

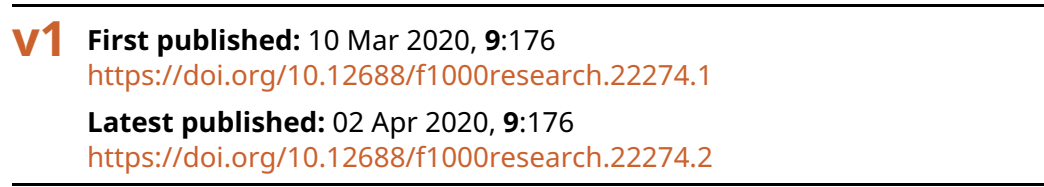

\section{Abstract}

Background: Attenuated total reflection-Fourier transform infrared (ATR-FTIR) spectroscopy is a rapid quantitative method which has been applied for pharmaceutical analysis. This work describes the utility of first derivative ATR-FTIR spectroscopy in the quantitative determination of diclofenac sodium tablets.

Methods: This analytical quantitative technique depends on a first derivative measurement of the area of infrared bands corresponding to the CO stretching range of $1550-1605 \mathrm{~cm}^{-1}$. The specificity, linearity, detection limits, precision and accuracy of the calibration curve, the infrared analysis and data manipulation were determined in order to validate the method. The statistical results were compared with other methods for the quantification of diclofenac sodium.

Results: The excipients in the commercial tablet preparation did not interfere with the assay. Excellent linearity was found for the drug concentrations in the range $0.2-1.5 \mathrm{w} / \mathrm{w} \%$. $\left(r^{2}=0.9994\right)$. Precision of the method was assessed by the repeated analysis of diclofenac sodium tablets; the results obtained showed small standard deviation and relative standard deviation values, which indicates that the method is quite precise. The high percentage of recovery of diclofenac sodium tablets $(99.81,101.54$ and $99.41 \%$ ) demonstrate the compliance of the obtained recoveries with the pharmacopeial percent recovery. The small limit of detection and limit of quantification values ( 0.0528 and $0.1599 \mathrm{w} / \mathrm{w} \%$, respectively) obtained by this method indicate the high sensitivity of the method.

Conclusions: First derivative ATR-FTIR spectroscopy showed high accuracy and precision, is considered as nondestructive, green, low cost and rapid, and can be applied easily for the pharmaceutical quantitative determination of diclofenac sodium tablet formulations.

\section{Keywords}

Diclofenac sodium tablet, FTIR spectroscopy, infrared quantitative analysis, first derivative, method development

\section{Open Peer Review

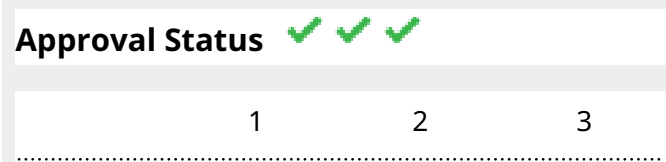 \\ version 2 \\ (revision) \\ 02 Apr 2020 \\ version 1 \\ 10 Mar 2020

view

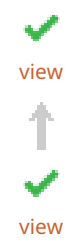 \\ 1. Hasan Aldewachi, University of Mosul, Mosul, Iraq Yasser Fakhri Mustafa (iD), University of Mosul, Mosul, Iraq Hasan Aldewachi iD, University of Mosul, Mosul, Iraq \\ 2. Baker Jawabrah Al-Hourani, Embry-Riddle Aeronautical University, Prescott, USA \\ 3. Mokhtar M. Mabrouk, Tanta University, Tanta, Egypt}

Any reports and responses or comments on the article can be found at the end of the article. 


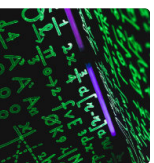

This article is included in the Mathematical,

Physical, and Computational Sciences

collection.

Corresponding author: Khairi M. S. Fahelelbom (khairi.mustafa@aau.ac.ae)

Author roles: Fahelelbom KMS: Conceptualization, Formal Analysis, Methodology, Project Administration, Writing - Original Draft Preparation; Saleh A: Data Curation, Investigation, Methodology, Supervision, Writing - Review \& Editing; Mansour R: Investigation, Methodology, Software; Sayed S: Data Curation, Methodology, Software

Competing interests: No competing interests were disclosed.

Grant information: The author(s) declared that no grants were involved in supporting this work.

Copyright: $\odot 2020$ Fahelelbom KMS et al. This is an open access article distributed under the terms of the Creative Commons Attribution License, which permits unrestricted use, distribution, and reproduction in any medium, provided the original work is properly cited.

How to cite this article: Fahelelbom KMS, Saleh A, Mansour R and Sayed S. First derivative ATR-FTIR spectroscopic method as a green tool for the quantitative determination of diclofenac sodium tablets [version 1; peer review: 2 approved] F1000Research 2020, 9:176 https://doi.org/10.12688/f1000research.22274.1

First published: 10 Mar 2020, 9:176 https://doi.org/10.12688/f1000research.22274.1 


\section{Introduction}

Diclofenac sodium (DS) is a nonsteroidal anti-inflammatory drug (NSAID) that is known for its potent pharmacologic activity. It is analgesic and also ameliorates acute and subchronic inflammation. The drug plays a unique dual inhibitory role simultaneously on cyclo-oxygenase (COX) and lipoxygenase enzymes $^{1}$. The drug is widely marketed under a variety of generic and brand names and is available in several dosage forms. The chemical structure of DS is shown in Figure 1, the IUPAC nomenclature is 2-[(2,6 dichlorophenyl)aminophenyl]acetic acid sodium salt.

Several quantitative analytical methods have been implemented to test the active pharmaceutical ingredient (API) of DS in its various marketed dosage forms. These quantitative approaches include high performance liquid chromatography ${\text { (HPLC })^{2-4} \text {, gas chromatography }}^{5}, \mathrm{UV}-$ visible spectrophotometry ${ }^{6}$, spectrofluorometry $^{7}$, densitometry ${ }^{8}$, potentiometry $^{8,9}$, and Raman spectroscopy ${ }^{10,11}$. The HPLC methods were also employed by the official US and British pharmacopeias for the analysis of $\mathrm{DS}^{12,13}$.

However, until recently, few reports have investigated and explored the capability and feasibility of infrared spectroscopy in its quantitative approach as a potential alternative to the aforementioned classic procedures ${ }^{14}$. This work aims to expand on previous reports exploring quantitative Fourier transform infrared (FTIR) approaches to quantitatively determine the APIs in a number of DS tablet dosage forms.

Traditionally, infrared spectroscopy has been extensively used in a qualitative manner. Elucidation of chemical composition has usually been achieved by analyzing incident radiation absorptions at a specific wavelength. Hence, the technique proves to be a powerful detector of functional groups. Each functional group is known to have its own distinguishable IR signature.

During the last few decades, there has been an exponential growth in the quantitative applications of IR spectroscopy ${ }^{15}$.

The technique has proved to be an appealing alternative to examine DS APIs in terms of quantitative outcomes. The results of numerous reports have indicated that FTIR offers unparalleled advantages over other techniques, which makes it a versatile alternative. The technique is inherently fast and covers a wide wavenumber range. It is also non-destructive and high resolved spectra can be obtained for almost all types of samples ${ }^{16}$. Simultaneous analysis of sample matrices<smiles>[NH3+]OC(=O)Cc1ccccc1Nc1c(Cl)cccc1Cl</smiles>

Figure 1. Chemical formula of diclofenac sodium. does not necessary require special sample preparation using challenging and lengthy procedures ${ }^{17}$. The technique is environmentally friendly as a result of the lack of any need for hazardous solvents or reagents ${ }^{18}$. The quality of results are comparable to most powerful techniques and the cost of routine analysis is extremely economical ${ }^{19}$.

Published research in this regard relies on the attenuated total reflection (ATR) sampling technique of modern FTIR spectrometers. ATR allows recording of an FTIR spectrum of solid and liquid samples directly without any further preparations ${ }^{20}$. Nevertheless, the sampling of DS still requires pressing an accurately measured amount of the drug or its commercial dosage into a potassium bromide $(\mathrm{KBr})$ disc to recode perfect spectra. Herein, the work retested the technique and expanded its capabilities by examining the direct spectral recording using a powder of DS (and its commercial formulations) mixed with $\mathrm{KBr}$ samples ${ }^{21}$. The new proposal simplifies the use of the ATR-FTIR technique tremendously. The exclusion of $\mathrm{KBr}$ disk sampling in each run will ultimately improve the procedure in terms of the time that the overall runs require. Consequently, modern FTIR instruments are affordable and this work proves powder mixtures or thin film samples produce comparable results, implying the unnecessity of $\mathrm{KBr}$ discs or press machines.

The evolution of quantitative capabilities of FTIR techniques may be attributable to the vast instrumentation advancements associated with powerful computers. Additionally, sampling techniques including flow analysis (FA) and ATR have been revolutionized to allow for analysis of almost any sample type - solids, liquids, solutions, gases and vapors - directly.

Quantitative FTIR has been successfully implemented in several areas of industrial pharmacy. It has been evolving as the potential technique of quality control protocols, in particular, analysis of APIs in a broad spectrum of pharmaceutical dosage forms and formulations ${ }^{14}$. The technique's inherent characteristics and nature bears unequivocally bright prospects. It is considered a purely green analytical chemistry technique. It is fast, easy to operate by a moderately experienced technician, can analyze any sample with little to no preparation, covers a wide range of spectrums to analyze most pharmaceutical products, has high resolution and is nondestructive. Importantly, it is environmentally friendly since no solvent or harmful reagents are required for the complete analysis ${ }^{22}$.

This work also demonstrates and utilizes modern spectrometers' powerful function of the first derivative spectra. The function provided the basic tool that allows the spectrometer resolution to be tuned to the degree required to greatly enhance the band separation of each spectrum. In this work, the ATR-FTIR spectrum of the pure DS was recorded. The powerful data processing and acquisition software associated with the spectrometer allowed the first derivative spectra to be obtained. The first derivative spectra indicated the degree of IR band overlapping within each spectrum. The selection of the IR band that best correlates with the concentration of DS without any interference of other bands is based solely on the first derivative spectra. 


\section{Methods}

Materials and reagents

IR spectroscopic-grade potassium bromide was checked prior to usage through the loss on drying method based on the recommended British Pharmacopia (BP) procedure ${ }^{13}$, which involves introducing $1 \mathrm{~g}$ of the sample into a dry bottle, reheating and reweighing until a constant weight is obtained.

Reference DS chemical standard was provided by Neopharma Pharmaceutical Manufacturing, Abu Dhabi, UAE. Three different DS commercial tablets were obtained from local pharmacies in Al Ain city, UAE, namely: Rumafen (diclofenac sodium $50 \mathrm{mg}$ ); Olfen TM 50 (diclofenac sodium $50 \mathrm{mg}$ ); and Diclogesic 50 (diclofenac sodium $50 \mathrm{mg}$ ).

\section{Equipment}

The FTIR instrument IRAffinity-1 CE (Shimadzu®, Kyoto, Japan), equipped with MiracleTM Single Reflection Horizontal ATR Accessory (Pike® Technologies) and IResolution Software (Shimadzu, version 1.60; Parameters: Measurement mode: \% transmittance; Apodization: Happ-Genzel; No of scans: 15; Resolution: 16.0; Range $\left(\mathrm{cm}^{-1}\right)$ : Min 700, Max 2000), was used for the screening and quantitative analysis in this study. Non-proprietary spreadsheet processing software could be used to analyze the raw data obtained. The samples were dried in an oven (WiseVen ${ }^{\circledR}$, Won-032, S. Korea) and an analytical balance (AUW220D, Shimadzuß) was used for all weights.

\section{Calibration curve}

A calibration curve was prepared from six different DS standard concentrations within the range of $0.2-1.0 \% \mathrm{w} / \mathrm{w}$. An appropriate quantity of DS was diluted with potassium bromide to get each concentration and was thoroughly ground in a mortar for $10 \mathrm{~min}$ to ensure sample homogeneity. Infrared spectra of each measurement were converted to the first derivative spectra. The area under the curve (AUC) of each calibration standard was measured in the range $1550-1605 \mathrm{~cm}^{-1}$. This band corresponds to the CO stretching of carboxylic sodium salts.

Quantitative determination of diclofenac sodium tablets To determine the API content for the commercial tablets in this study, ten tablets were accurately and individually weighed, then the whole sample was finely powdered for each brand. Samples were prepared by mixing and thoroughly grinding an appropriate quantity of each tablet powder with potassium bromide to get $0.5 \% \mathrm{w} / \mathrm{w}$ of DS. $100 \mathrm{mg}$ of the mixture was transferred to the diamond ATR top plate of the spectrometer over the diamond crystal. IR measurements were run in triplicate and the average was calculated for each run.
Data analysis

SPSS version 21 (SPSS Inc., Chicago, IL, USA) was used for descriptive and analytical statistics.

\section{Results and discussion}

\section{Method validation}

The proposed ART-FTIR analytical method was validated according to the International Council for Harmonization of Technical Requirements for Pharmaceuticals for Human Use guidelines $^{23}$.

Validation of the method included the following parameters: linearity, selectivity, limit of detection (LOD), limit of quantification (LOQ), accuracy, precision and robustness.

\section{Linearity}

The proportional relationship between the AUC and concentration was evaluated by constructing a linear regression of five concentrations $(0.2,0.4,0.6,0.8,1 \%)$. The excellent linearity obtained was indicated by the correlation coefficient value $r^{2}=0.9994$. Table 1 shows the data analysis of the DS calibration curve and the linear relationship is presented in Figure $3 \mathrm{a}$ and $3 \mathrm{~b}$.

\section{Selectivity}

Selectivity is used to justify the ability of the method to accurately quantify the existence of DS in the presence of other pharmaceutical additives. The selectivity of our method was verified by comparing diclofenac tablets to pure diclofenac. Bands used for quantification were only unique to diclofenac. Figure $2 \mathrm{a}$ and $2 \mathrm{~b}$ represents the direct and first derivative of ART-FTIR spectra, which indicate the CO high absorption band at 1550-1605 $\mathrm{cm}^{-1}$. The first derivative shows a clear band without any overlapping from the other peaks. Additionally, Figure $3 \mathrm{c}$ and $3 \mathrm{~d}$ represents the direct and first derivative spectra of Olfen tablet, respectively. The obtained data represented in these figures showed no interference from the excipients and additives present in the tablet formulation.

\section{LOD and LOQ}

The LOD is the lowest amount of analyte at which that an analyte can be detected. While the LOQ is the lowest amount of analyte at which an analyte can be measured accurately and precisely.

$$
\begin{array}{ll}
\mathrm{LOD}=3.3 \sigma / \mathrm{S} & \text { Equation 1 } \\
\mathrm{LOQ}=10 \sigma / \mathrm{S} & \text { Equation 2 }
\end{array}
$$

Where $\sigma$ is the standard deviation and $\mathrm{S}$ is the slope.

By applying Equation 1 and Equation 2, the obtained values of LOD and LOQ were $0.052757 \%$ and $0.159869 \%$, respectively

Table 1. Data analysis of diclofenac sodium calibration curve.

\begin{tabular}{|l|l|l|l|l|l|}
\hline Wavelength $\left(\mathbf{c m}^{-1}\right)$ & Concentration range (\% w/w) & Regression equation & R2 & LOD (\%) & LOQ (\%) \\
\hline $1550-1605$ & $0.2-1.5$ & $Y=1.375 X-0.014$ & 0.9994 & 0.0528 & 0.1599 \\
\hline
\end{tabular}




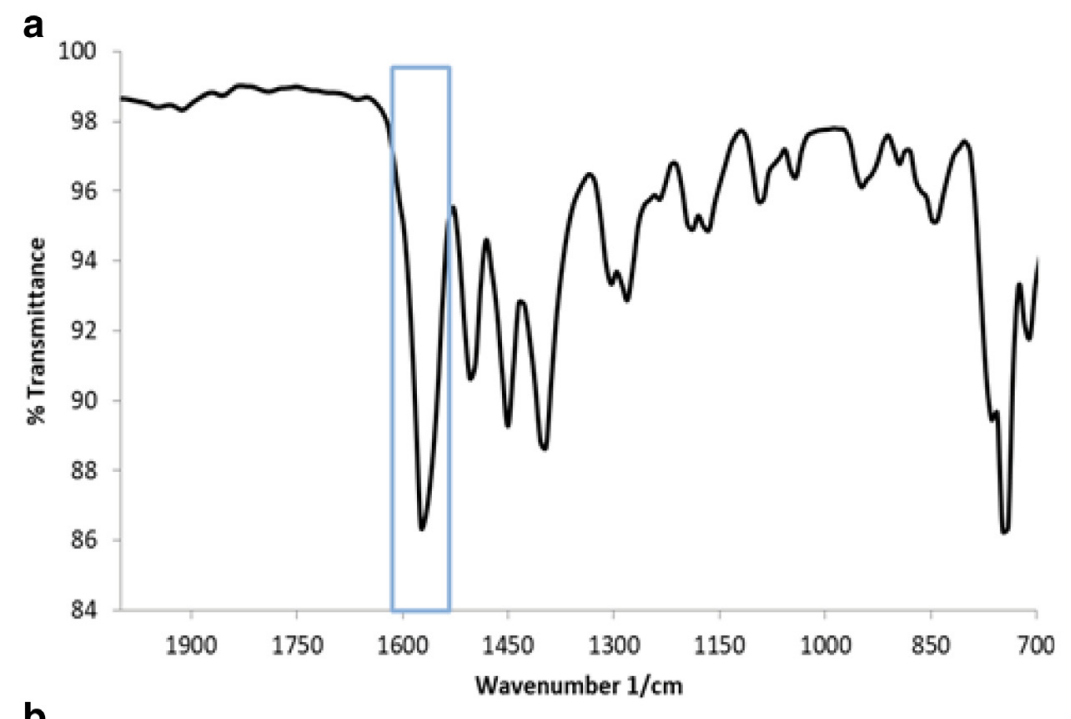

b

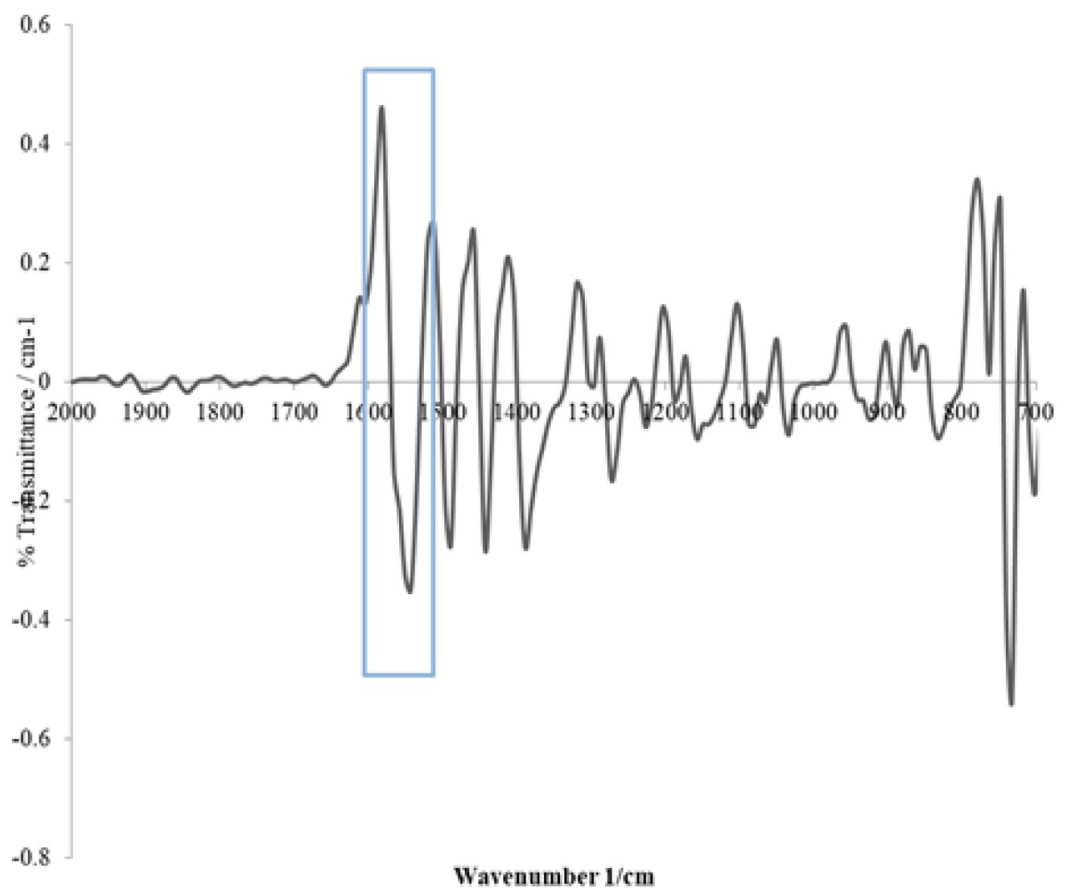

Figure 2. (a) Spectrum of pure diclofenac sodium mixed with potassium bromide $(\mathrm{KBr} ; 0.6 \% \mathrm{w} / \mathrm{w})$. (b) First derivative spectrum of pure diclofenac sodium mixed with $\mathrm{KBr}(0.6 \% \mathrm{w} / \mathrm{w})$.

(Table 1). The low values for both parameters indicate the high sensitivity of this study ${ }^{24}$.

\section{Accuracy}

The accuracy of the method was evaluated using the calibration method. Three different brands (A, B, and C) of diclofenac tablets were analyzed. 10 tablets of each brand were crushed to a fine powder and mixed with $\mathrm{KBr}$ to prepare $0.5 \% \mathrm{w} / \mathrm{w}$ diclofenac/KBr. Mean recovery of Tablets $\mathrm{A}, \mathrm{B}$ and
C was calculated to be $99.8 \%, 101.5 \%$ and 99.4 , respectively (Table 2). The obtained results are in agreement with USP and $\mathrm{BP}$ recovery range for DS tablets ${ }^{12,13}$.

\section{Precision and robustness}

The precision of the method was assessed by repeatability and intermediate precision studies. Repeatability and robustness analysis were performed by analyzing the $0.5 \% \mathrm{w} / \mathrm{w}$ (mixed with $\mathrm{KBr}$ ) peak areas (AUC) of each brand. Three readings 

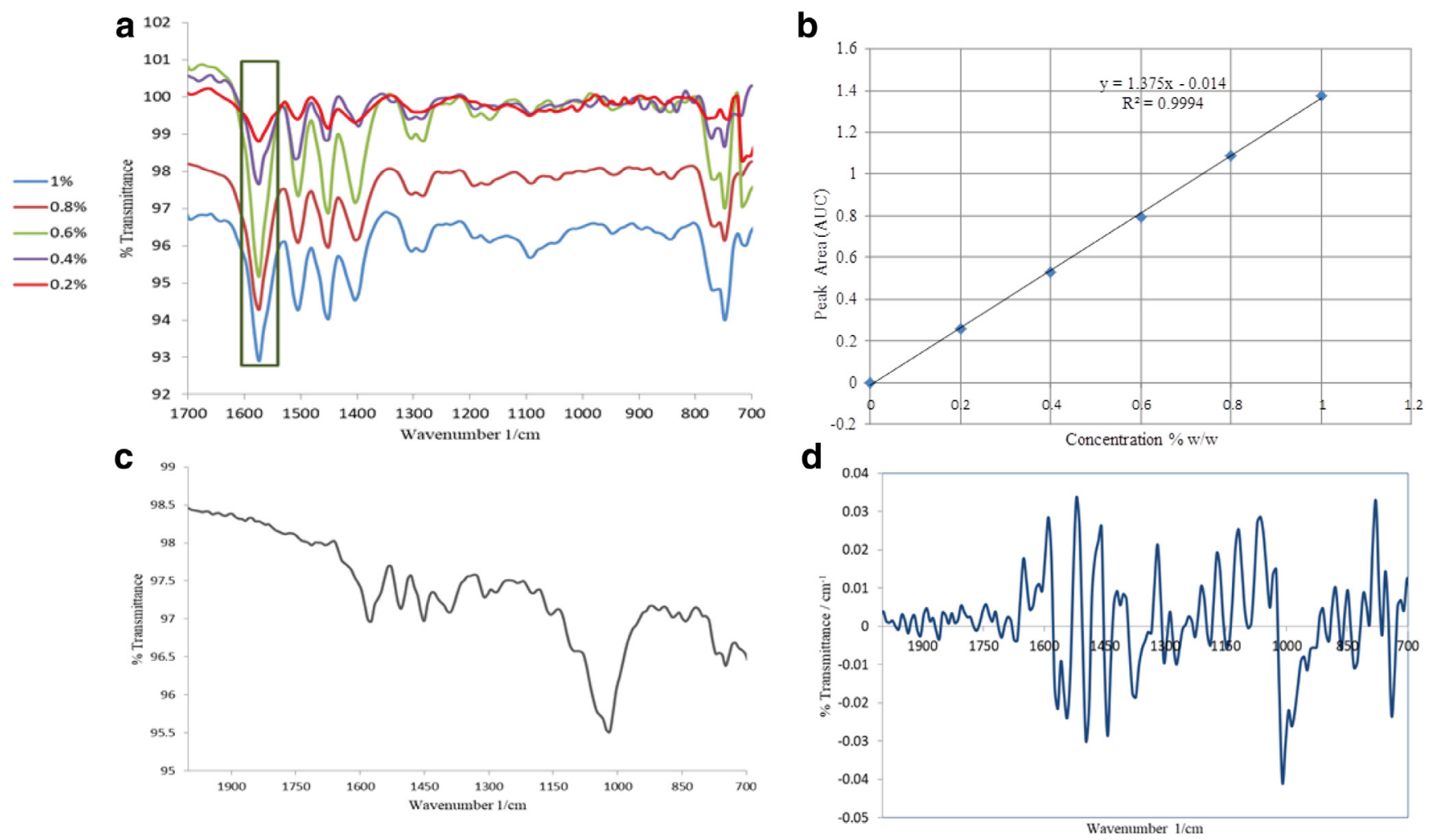

Figure 3. (a) Overlay spectra of different diclofenac sodium reference substance concentrations. (b) Calibration curve of diclofenac sodium showing the linear regression equation. (c) Direct Fourier transform infrared (FTIR) spectra of Olfen Tablet. (d) First derivative FTIR spectra of Olfen Tablet.

Table 2. FTIR quantitative analysis of different DS tablet dosage forms.

\begin{tabular}{|l|l|l|l|}
\hline $\begin{array}{l}\text { Samples of tablet } \\
\text { dosage forms }\end{array}$ & SD-API content \% w/w & Recovered SD-API \% w/w & \% Recovery \\
\hline Sample (A) & 0.511 & 0.505 & 98.82 \\
\hline Diclogesic $50 \mathrm{mg}$ & 0.511 & 0.508 & 99.41 \\
\hline & 0.511 & 0.517 & 101.17 \\
\hline & Average & & 99.81 \\
\hline Sample (B) & $0.5 \%$ & 0.499 & 99.80 \\
\hline Olfen 50 mg (B) & $0.5 \%$ & 0.517 & 102.80 \\
\hline & $0.5 \%$ & 0.510 & 102.00 \\
\hline Sample (C) & Average & & 101.54 \\
\hline Rumafen 50 mg (C) & 0.514 & 0.505 & 98.24 \\
\hline & 0.511 & 0.511 & 99.41 \\
\hline & Average & 0.514 & 100.58 \\
\hline
\end{tabular}

FTIR, Fourier transform infrared; DS, diclofenac sodium; API, active pharmaceutical ingredient; SD, standard deviation. 
for each sample were recorded and analyzed in one day (for the intra-day precision) and two readings were recorded on two consecutive days (for the inter-day precision). The results were very precise, as represented by the standard deviations, which ranged between 0.008343 and 0.020255 , while the percent relative standard deviation (\% RSD) was between 1.26095 and 3.03781 .

\section{Conclusion}

The proposed first derivative ATR-FTIR spectroscopic method is considered as a green, nondestructive, low cost, fast, sensitive, accurate and precise technique for the quantitative analysis of DS in its pure and tablet dosage formulation and can be easily applied for quantitative determination and quality control.

\section{Data availability}

Underlying data

Harvard Dataverse: Utility of ATR-FTIR Spectroscopic Method as Green Tool for Pharmaceutical Analysis of Diclofenac Sodium Tablets. https://doi.org/10.7910/DVN/6SJZ7W25.

Data are available under the terms of the Creative Commons Zero "No rights reserved" data waiver (CC0 1.0 Public domain dedication)

\section{Acknowledgments}

The authors are thankful to the Neopharma Pharmaceutical Co., Abu Dhabi, UAE for providing the diclofenac sodium reference standard.
1. Scholer DW, Ku EC, Boettcher I, et al.: Pharmacology of diclofenac sodium. Am $J$ Med. 1986; 80(4B): 34-38

PubMed Abstract | Publisher Full Text

2. Alquadeib BT: Development and validation of a new HPLC analytical method for the determination of diclofenac in tablets. Saudi Pharm J. 2019; 27(1): $66-70$.

PubMed Abstract | Publisher Full Text | Free Full Text

3. Arisoy GG, Dural E, Mergen G, et al: Development and Validation of HPLC-UV Method for the Determination of Diclofenac in Human Plasma with Application to a Pharmacokinetic Study. Turk J Pharm. 2016; 13(3): 292-299.

Reference Source

4. Dongala T, Palakurthi AK, Velaveni KK, et al: Development and Validation of RP-HPLC Method for Simultaneous Determination of Diclofenac Potassium and its Process Related Impurities in Solid Oral Dosage Form. J Chromatogr Sep Tech. 2018; 9: 412

Publisher Full Text

5. Yilmaz B, Ciltas U: Determination of diclofenac in pharmaceutical preparation by voltammetry and gas chromatography methods. J Pharm Anal. 2015; 5(3): 153-160.

PubMed Abstract | Publisher Full Text | Free Full Text

6. Uzochukwu IC, Nzegbunam SO: Visible Spectrophotometric and Thermodynamic Studies of Diclofenac: Charge-Transfer Complexation with 2 , 3 Dichloro-5, 6-dicyano, 1, 4-benzoquinone. Tropical J Pharm Rese. 2015; 14(3): 519-525.

Publisher Full Text

7. Castillo M, Bruzzone L: Indirect fluorometric determination of diclofenac sodium. Anal Sci. 2006; 22(3): 431-3.

PubMed Abstract | Publisher Full Text

8. Parys W, Pyka-Pajak A, Dołowy M: Application of Thin-Layer Chromatography in Combination with Densitometry for the Determination of Diclofenac in Enteric Coated Tablets. Pharmaceuticals (Basel). 2019; 12(4): pii: E183. PubMed Abstract | Publisher Full Text | Free Full Text

9. Oliveira MC, Bindewald EH, Marcolino LH Jr, et al.: Potentiometric determination of Diclofenac using an ion-selective electrode prepared from polypyrrole films. J Electroanal Chem. 2014; 732: 11-16. Publisher Full Text

10. Elbalkinya HT, Yehiab AM, Riada SM, et al:: Potentiometric diclofenac detection in wastewater using functionalized nanoparticles. Microchem J. 2019; 145: 90-95. Publisher Full Text

11. Szostak R, Mazurek S: Quantification of active ingredients in suppositories by FT-Raman spectroscopy. Drug Test Anal. 2013; 5(2): 126-129. PubMed Abstract | Publisher Full Text

12. United States Pharmacopeial Convention, 37th edn. and the national formulary, 32nd edn. United States Pharmacopeial Convention: Rockville, MD. 2013.
13. British Pharmacopoeia: Her Majesty's Stationery Office: London, UK. 2013. Reference Source

14. Nugrahani I, Dillen N: Rapid assay development of diclofenac sodium coated tablet assay using FTIR compared to HPLC method. Int J App Pharm. 2018; 10(4): 43-50. Publisher Full Text

15. Cadet F, Garrigues S, de la Guardia M: Quantitative Analysis, Infrared in the Encyclopedia of Analytical Chemistry. John Wiley \& Sons, Ltd. 2012. Publisher Full Text

16. Che Man YB, Syahariza ZA, Rohman A: Chapter 1. Fourier transform infrared (FTIR) spectroscopy: development, techniques, and application in the analyses of fats and oils. In Fourier Transform Infrared Spectroscopy. edited by Oliver J. Ress, Nova Science Publishers, New York: USA. 2010; 1-26. Reference Source

17. Moros J, Garrigues S, de la Guardia M: Vibrational spectroscopy provides a green tool for multi-component analysis. Trends Anal Chem. 2010; 29(7): 578-591. Publisher Full Text

18. de la Guardia M: Green analytical chemistry. Trends Anal Chem. 2010; 29(7): 577 Publisher Full Text

19. Blanco M, Peguero A: Analysis of pharmaceuticals by NIR spectroscopy without a reference method. Trends Anal Chem. 2010; 29(10): 1127-1136. Publisher Full Text

20. Bunaciu A, Abou-Enein HY, Fleschin S: Application of Fourier Transform Infrared Spectrophotometry in Pharmaceutical Drugs Analysis. Appl Spectrosc Rev. 2010; 45: 206-219. Publisher Full Text

21. Nugrahani I, Manosa EY, Chintya L: FTIR-derivative as a green method for simultaneous content determination of caffeine, paracetamol, and acetosal in a tablet compared to HPLC. Vib Spectrosc. 2019; 104: 102941. Publisher Full Text

22. Mazurek S, Szostak R: Quantitative determination of diclofenac sodium and aminophylline in injection solutions by FT-Raman spectroscopy. J Pharm Biomed Anal. 2006; 40(5): 1235-1242. PubMed Abstract | Publisher Full Text

23. International Conference on Harmonization (ICH) of technical requirements for registration of pharmaceuticals for human use, Validation of analytical procedures: Text and methodology Q2 (R1). ICH Geneva, Switzerland. 2005. Reference Source

24. Shrivastava A, Gupta VB: Methods for the determination of limit of detection and limit of quantitation of the analytical methods. Chron Young Sci. 2011; 2(1): 21-25. Publisher Full Text

25. Fahelelbom KM, Saleh A, Mansour R, et al: "Utility of ATR-FTIR Spectroscopic Method as Green Tool for Pharmaceutical Analysis of Diclofenac Sodium Tablets". Harvard Dataverse, V1, UNF:6:5J6Gk08vUOY7ReTP51001g== [fileUNF]. 2020. http://www.doi.org/10.7910/DVN/6SJZ7W 


\section{Open Peer Review}

\section{Current Peer Review Status:}

\section{Version 1}

Reviewer Report 19 March 2020

https://doi.org/10.5256/f1000research.24569.r61173

(C) 2020 Al-Hourani B. This is an open access peer review report distributed under the terms of the Creative Commons Attribution License, which permits unrestricted use, distribution, and reproduction in any medium, provided the original work is properly cited.

\section{Baker Jawabrah Al-Hourani}

Department of Biology and Chemistry, Embry-Riddle Aeronautical University, Prescott, AZ, USA

Quantitative determination of diclofenac sodium in tablet dosage was carried out by using the ATRFTIR device. This is a unique methodology and considered as a part of the green chemistry field. The work is clearly presented, reproducible, clean, and full of important information, which can be used by any third party.

First comment is regarding a typo in the first paragraph in the introduction, line 5: Please change "cyclo-oxygenase" to "cyclooxygenase".

Second comment is regarding the scientific content of the same paragraph, line 5: Please specify the type of the cyclooxygenase: $1 / 2$ or both. The same thing regarding the lipoxygenase enzyme.

Is the rationale for developing the new method (or application) clearly explained?

Yes

Is the description of the method technically sound?

Yes

Are sufficient details provided to allow replication of the method development and its use by others?

Yes

If any results are presented, are all the source data underlying the results available to ensure full reproducibility?

Yes

Are the conclusions about the method and its performance adequately supported by the findings presented in the article? 
Yes

Competing Interests: No competing interests were disclosed.

Reviewer Expertise: Drug design and Discovery Research.

I confirm that I have read this submission and believe that I have an appropriate level of expertise to confirm that it is of an acceptable scientific standard.

Author Response 20 Mar 2020

Khairi Salem,

Authors Response for Comments of reviewers 1 - Yasser Fakhri Mustafa and Hasan

Aldewach:

1. All data in Table 2 is represented in $\% \mathrm{w} / \mathrm{w}$. Sample B data in the Table 2 was corrected according to the reviewers comments in order to be consistent with samples $A$ and $C$.

2. The standard deviations (SD) and relative standard deviations (RSD) have been summarized under precision and robustness section.

3. This work describes the Utility of ATR-FTIR for the analysis of uncoated tablet of diclofenac sodium, as the excipients is not interfering in the analysis of active ingredient we expect that the coating material may need certain extraction process.

Authors Responses for Comments of reviewer 2 Baker Jawabrah Al-Hourani:

DS is known to be nonselective COX inhibitor. The inhibition of COX-1 (constitutive isoform) is assumed to be the main cause of undesirable side effects of the drug. However; the inhibition effects of the COX-2 (inducible isoform) yield the desired effects. The exceptional potency of DS among other NSAIDs was explained on the basis of the additional 5lipoxygenase (5-LOX) indirect inhibitory effect of the drug.

Reference

Fiorucci S, Meli R, Bucci M, Cirino G, Dual inhibitors of cyclooxygenase and 5-lipoxygenase. A new avenue in anti-inflammatory therapy, Biochemical Pharmacology. 2002; 62(11):1433-8, DOI: 10.1016/S0006-2952(01)00747-X

Author : Khairi M.S. Fahelelbom

Competing Interests: No competing interests were disclosed.

Reviewer Report 16 March 2020

https://doi.org/10.5256/f1000research.24569.r61176 
(C) 2020 Mustafa $Y$ et al. This is an open access peer review report distributed under the terms of the Creative Commons Attribution License, which permits unrestricted use, distribution, and reproduction in any medium, provided the original work is properly cited.

\section{Yasser Fakhri Mustafa}

Department of Pharmaceutical Chemistry, College of Pharmacy, University of Mosul, Mosul, Iraq Hasan Aldewachi

Department of Pharmaceutical Chemistry, College of Pharmacy, University of Mosul, Mosul, Iraq

This study aimed to investigate one of the green analytical chemistry tools for quantitative determination of Diclofenac sodium (DS) in tablet dosage forms by using ATR-FTIR technique. The novelty of this work arises from excluding the need for sample preparation like the using of $\mathrm{KBr}$ discs. I find the work interesting, informative, and worthy to be indexed. However I have some concerns/suggestions after carefully reading the report.

1. $2^{\text {nd }}$ column in Table 2 needs consistency in the expression of concentration of DS because sample $B$ is expressed in terms of $\%$, while samples A\&C were expressed as quantities.

2. I would rather suggest expressing the standard deviation (SD)and relative standard deviation (RSD) in a table as follows:

Sample name SD RSD

Sample A $\quad 0.0083 \quad 1.26 \%$

Sample B

Sample C

3. Would the authors be able to state whether this method suits coated tablet forms of DS?

Is the rationale for developing the new method (or application) clearly explained?

Yes

Is the description of the method technically sound?

Yes

Are sufficient details provided to allow replication of the method development and its use by others?

Yes

If any results are presented, are all the source data underlying the results available to ensure full reproducibility?

Yes

Are the conclusions about the method and its performance adequately supported by the findings presented in the article? 
Competing Interests: No competing interests were disclosed.

Reviewer Expertise: Medicinal Chemistry, Chemistry of natural products, Pharmaceutical analysis, Organic synthesis, and instrumentations.

We confirm that we have read this submission and believe that we have an appropriate level of expertise to confirm that it is of an acceptable scientific standard.

Author Response 20 Mar 2020

Khairi Salem,

Authors Response for Comments of reviewers 1 - Yasser Fakhri Mustafa and Hasan Aldewach:

1. All data in Table 2 is represented in $\% \mathrm{w} / \mathrm{w}$. Sample B data in the Table 2 was corrected according to the reviewers comments in order to be consistent with samples $A$ and $C$.

2. The standard deviations (SD) and relative standard deviations (RSD) have been summarized under precision and robustness section.

3. This work describes the Utility of ATR-FTIR for the analysis of uncoated tablet of diclofenac sodium, as the excipients is not interfering in the analysis of active ingredient we expect that the coating material may need certain extraction process.

\section{Authors Responses for Comments of reviewer 2 Baker Jawabrah Al-Hourani:}

DS is known to be nonselective COX inhibitor. The inhibition of COX-1 (constitutive isoform) is assumed to be the main cause of undesirable side effects of the drug. However; the inhibition effects of the COX-2 (inducible isoform) yield the desired effects. The exceptional potency of DS among other NSAIDs was explained on the basis of the additional 5lipoxygenase (5-LOX) indirect inhibitory effect of the drug.

Reference

Fiorucci S, Meli R, Bucci M, Cirino G, Dual inhibitors of cyclooxygenase and 5-lipoxygenase. A new avenue in anti-inflammatory therapy, Biochemical Pharmacology. 2002; 62(11):1433-8, DOI: 10.1016/S0006-2952(01)00747-X

Author : Khairi M.S. Fahelelbom

Competing Interests: No competing interests were disclosed. 
The benefits of publishing with F1000Research:

- Your article is published within days, with no editorial bias

- You can publish traditional articles, null/negative results, case reports, data notes and more

- The peer review process is transparent and collaborative

- Your article is indexed in PubMed after passing peer review

- Dedicated customer support at every stage

For pre-submission enquiries, contact research@f1000.com 